\title{
INFORME
}

\section{de la Secretaría sobre actividades de la Junta Directiva en el período compren- dido de 1954 a 1955}

\author{
Por el doctor Miguel A. Fernández Bastidas
}

La Secretaría General de la Sociedad Colombiana de Obstetricia y Ginecología, en atención a que la presente reunión es la última que corresponde al período de ejercicio de la actual Junta Directiva compuesta por los doctores José del Carmen Acosta, Rodulfo Camero, Miguel A. Fernández Bastidas, Alvaro Espinosa y Espinosa y Santiago Lleras Codazzi, como Presidente, Vicepresidente, Secretario General de Actas y Tesorero, respectivamente, presenta ante esta Asamblea General un recuento detallado de las actividades desarrolladas durante el período comprendido entre febrero de 1954 y febrero de 1955, a fin de que sea juzgada la labor cumplida por dicha Junta.

De acuerdo con la finalidad estatutaria que consagra a esta Sociedad una función gremial, administrativa-social y científica y principiando por ésta última sin duda la más importante para nosotros, informamos que esta Mesa Directiva no ha ahorrado esfuerzos para ser fiel al programa trazado desde el día de su posesión, estimulando al máximo las labores de investigación llevadas a cabo en equipo, ya iniciadas en buena hora por la Junta anterior y que a continuación tendremos el agrado de presentar ante ustedes ya como una feliz realización.

En primer lugar y ya colocadas en segundo plano las exaltadas reuniones con fines casi exclusivamente gremiales que la necesidad impuso cuando existían problemas no definidos con los Seguros Sociales; nuestro principal empeño fue que en todas las reuniones ordinarias predominaran los temas científicos de in- 
terés general tanto para Ginecólogos como para Obstetras a fin ce despertar un mayor espíritu de investigación y de controversia científica que coloque a nuestro país a la altura que se merece dentro de las naciones de este continente.

Así, pues, la lectura de trabajos inéditos sometidos a discusión entre los asistentes a las reuniones, trajo como consecuencia indudable el mayor aprovechamiento de historias clínicas que de otra manera no habrían tenido un comentario tan amplio.

Entramos así, pues, a enumerar cronológicamente dichas actividades.

MARzo 11.- Presentación del informe preliminar que sobre el estudio de Toxemia gravídica se llevó a cabo en la Clínica Primero de Mayo de esta ciudad hecho por el doctor Miguel A. Fernández Bastidas.

ABRIL 10_- Monografía sobre "Ruptura del útero grávido", con numerosas historias extractadas del servicio de Protección Materno Infantil y presentadas por el doctor Rafael Hunda Cruz.

Mayo 10.- Consideraciones sobre "Intervenciones abdominales durante el embarazo", con historias extractadas del Servicio de Maternidad del Hospital de San José, por el doctor Alberto Villaneda soto.

Junio 3.- Monografía sobre "Concomitancia de várices y embarazo", presentada por los doctores Gonzalo Echeverry y Humberto $\mathrm{H}$. Correa. Con historias de la clientela particular y de servicios hospitalarios.

Julio 2.- Presentación de un informe sobre "El estado actual de la Obstetricia y Ginecología en algunos centros de Europa y los Estados Unidos", por el doctor Guillermo López Escobar.

Agosto 5.- "Comentario de un caso de fístula útero-vaginal concomitante con embarazo", presentado por el doctor Alvaro F'onnegra Miramón.

Septiembre 9.- Interesante informe sobre algunas observaciones en el Servicio Obstétrico del "Medical College of Georgia", con el doctor Richard Torpin, Profesor de Obstetricia de dicha con el doctor Richard Torpin, Profesor de Obstetricia de dicha Universidad.

Septiembre 9.- Informe sobre el Segundo Congreso Latinoamericano de Obstetricia y Ginecología celebrado en la ciudad de Sao Paulo, Brasil (11 al 16 de julio), presentado por el Presiclente de la Delegación doctor Miguel A. Fernández Bastidas.

OCtubRe 7.- Presentación del doctor Gustavo Escallón Cai- 
cedo de la Sociedad de Urología, por invitación especial de la Sociedad de Obstetricia y Ginecología con el trabajo "Neo-vejiga recto u operación de Lowsley modificada por Rueda".

Noviembre. 4.- Presentación del trabajo titulado: "Especificidad cito-hormonal de la fase folículo-luteínica", por el doctor Guillermo López Escobar, quien lo ilustró con la proyección de interesantes microfotografías.

Diciembre 9.- Presentación del trabajo "Estudio de cuarenta y cinco casos de cáncer del cuello uterino tratados quirúrgicamente en el Instituto Nacional de Cancerología", por el doctor Germán Jordán, con el que hacía opción a miembro de número.

Durante el mismo período la Sociedad se honró con el ingreso de los siguientes nuevos miembros de número:

Agosto 5.- Doctor Miguel Páez, con el trabajo "Algunas consideraciones sobre aplicaciones de forceps en la Clínica David Restrepo, de Bogotá".

Octubre 7.- Doctor Alfonso Salcedo, con el trabajo "Un año de jefatura de clínica ginecológica".

Octubre 7.- Doctor Camilo Arango Jaramillo, con el trabajo "Revista general de la endometriosis".

Octubre 7.- Doctor Luis Angulo Rodríguez, con el trabajo "Apreciaciones sobre el Schok en Obstetricia".

Noviembre 4.- Doctor Leopoldo Saavedra, con el trabajo "Cincuenta casos de metabolismo basal en el embarazo a término".

Diciembre. 9.- Doctor Germán Jordán, con el trabajo ya citado "Estudio de cuarenta y cinco casos de cáncer del cuello uterino tratados quirúrgicamente en el Instituto Nacional de Cancerología".

Durante este año la sociedad igualmente abrió un curso de trabajos científicos originales para enviar un representante oficial al II Congreso Latinoamericano, siendo favorecido por el jurado integrado por los doctores José del Carmen Acosta y Arturo Aparicio Jaramillo, el trabajo titulado "Técnica original de perineorrafia post-episiotomía”, del doctor Miguel A. Fernández Bastidas.

La revista de la Sociedad alcanzó el número 35, desde su funaación hecha por el doctor Rafael Ramirez Merchán; publicó ininterrumpidamente cada dos meses su número correspondiente, y gracias al extraordinario interés tomado por sus directores doctores Carlos Roberto Silva Mojica y Rođulfo Camero C., se logró la edición de un lujoso número extraordinario correspondiente a 
mayo y junio del 54, de las Memorias del Primer Congreso Nacional de Obstetricia y Ginecología celebrado en Bogotá en septiembre de 1953 bajo los auspicios de èsta Sociedad.

Igualmente, por inicitiativa de esta Secretaría y en colaboración con el Servicio de Obstetricia del Hospital San José, se llevaron a cabo reuniones anatomoclínicas de manera casi ininterrumpida en las cuales tomaron parte como ponentes entre otros los doctores Héctor Enrique Bernal, Jaime Afanador, Jorge Ortiz Gamboa y Belisario Calderón, etc.

La organización definitiva del equipo de médicos interesados en el estudio de la Toxemia gravídica se llevó a cabo, gracias a la colaboración obtenida por el Director de la Clínica Primero de Mayo, doctor Belisario Calderón, a quien se debe en gran parte la continuación de dichos estudios. De la misma manera se abrió una inscripción entre los obstetras de esa misma clínica para el estudio de la anestesia regional y su utilización en obstetricia. De ambos estudios pronto tendremos las primeras publicaciones.

Por último, esta secretaría, en colaboración íntima con la directiva de la revista, apoyó y fomentó las reuniones periódicas para el comentario de trabajos enviados para su publicación, así como también el comentario y resumen de revistas extranjeras, cuyos artículos de mayor interés fueron más tarde resumidos e insertados en la sección correspondiente de nuestra publicación.

La asistencia de delegaciones oficiales a dos importantes Congresos Internacionales de la especialidad, tales como el Segundo Congreso Latinoamericano celebrado en Sao Paulo, Brasil (cuyos detalles aparecen en el informe publicado en uno de los números de la revista de la Sociedad), y el Primer Congreso Venezolano de Obstetricia y Ginecología del cual esta misma noche tendremos noticias de boca del Presidente de nuestra Delegación coctor Rodulfo Camero; nos puede dar idea exacta del interés que esta Junta Directiva tomó por vincular la Sociedad estrechamente a las sociedades científicas análogas que funcionan en el Continente y con las cuales nos hallamos aún más comprometidos por hacer parte nuestro país de la Federación Latinoamericana de Sociedades de Obstetricia y Ginecologia (Flasog). Ya en el informe a que se hace referencia más arriba, se dio cuenta de la elección de Colombia como sede subsiguiente a la de México para la celebración del Cuarto Congreso Latinoamericano, compromiso que de ninguna manera podemos eludir, pues si así fuera per- 
deríamos casi definitivamente la oportunidad de celebrar dicho certamen en nuestro país.

La estrecha vinculación entre todos los especialistas del país por medio de circulares y boletines informativos sobre actividades médicas en el país y fuera de él, ha logrado alentar la creación de las filiales de la Sociedad en Cali, Cartagena y Bucaramanga, estando ya establecidas y en pleno funcionamiento las de Barrancuilla, Medellín y Santa Marta. Pero todas estas gestiones hechas con el sentido de que la Sociedad Colombiana de Obstetricia y Ginecología sea realmente "colombiana" y no sólo bogotana, no lograría su objetivo, si una misión especial con plenas autorizaciones, no les visitara y les ayudara a su organización con la experiencia ya lograda en Bogotá; de tal manera que la nueva Junta Directiva con el deseo de continuar estas labores de acercamiento entre todos los especialistas del país, debe darle suficiente importancia a esta labor por nosotros iniciada.

Por último, cabe señalar la postrer realización de esta Junta Directiva, cual fue el Primer curso de post-graduados organizado por nuestra Sociedad; que después de enormes esfuerzos pudimos ofrecer a todos los especialistas del país (70 inscripciones con un $26 \%$ de asistentes de fuera de Bogotá) con las figuras más connotadas de Europa y América que asistieron al último congreso venezolano y gracias al entusiasmo del doctor Fernando Tamayo, de la Vicepresidencia y la Secretaría General, tuvimos la oportunidad de oir a los doctores Raoul Palmer, de París; Chassar Moir, de Oxford (Inglaterra); T. Antoine, de Austria; W. Williams, de los Estados Unidos; Campos Da Paz, del Brasil, en sus estudios sobre la esterilidad; a Hermógenes Alvarez, Manuel Luis Pérez, D. Watteville en magistrales conferencias sobre dinámica uterina, anoxia fetal y dietética en obstetricia, y palabras tan autorizadas como las de Zuckermann y Salaber en el campo del cáncer ginecológico.

Como ya lo habíamos señalado al iniciar este informe, la actual Junta Directiva no solamente se preocupó por la finalidad científica, sino también por la gremial, habiendo logrado el día 19 de mayo de 1954 firmar el primer contrato de trabajo de la Sociedad con el Seguro Social, reglamentando en esta forma y por un plazo de un año prorrogable las relaciones existentes entre estas dos entidades. La nueva reglamentación establecida a raíz de la firma de este contrato, en la Clínica Primero de Mayo con turnos de 48 horas prestados por 3 obstetras, quienes van rotando 
jor grupos, benefició sin lugar a dudas a éstos, permitiéndoles poder dedicarse de manera más amplia a sus labores profesionales particulares (en el mes en la mayoría de los casos únicamente tienen cbligación a más de la consulta prenatal semanal de trabajar 48 horas) con un sueldo básico ligeramente inferior al percibido anteriormente con tiempo completo. Estando, pues, en vísperas de terminar el plazo por el que se firmó, es de capital importancia la forma como se haga la prórroga de éste, así, pues, la nueva Junta Directiva tiene la obligación para con los asociados de mejorar aún más las condiciones existentes logrando tarifas más justas dentro de la actual libertad de trabajo. Claro está que lo deseable hubiera sido desde el principio una mejor tarifa en este contrato, no ya del Seguro con cada obstetra en particular sino de aquél con una entidad de tanto prestigio como es la Sociedad, pero eso no quiere decir que después de un año de "prueba" la nueva Junta no logre un reajuste de tarifas.

Por último parécenos de importancia dar a conocer algo de la parte administrativa y que en casi su totalidad se debe a la Junta Directiva que hoy se retira. Como es de todos conocido, la Sociedad hace un año apenas contaba con una pequeña oficina cie Secretaría, donde se carecía de los elementos más indispensables; los fondos de la Sociedad manejados abnegadamente por nuestro actual Tesorero, ya reelegido en aquella oportunidad, dificultaba su contabilidad por la no existencia siquiera de una cuenta bancaria a nombre de la Sociedad. Hoy contamos con una oficina perfectamente organizada, con una dotación moderna completa, en uno de los edificios más céntricos de la ciudad, con servicio telefónico, equipo mimeográfico, con un cárdex completamente ordenado, con los records completos de todos los asociados, etc., etc. Oficina en la cual funciona conjuntamente todo lo relacionado con la revista de la Sociedad, en lo que tiene que ver con propaganda comercial y sección editorial, canjes, etc.

Damos por concluído este informe, invitando a los asociados a analizar el balance presentado por la Tesorería, en el cual de manera palpable podrán apreciar no ya nuestro avance en el campo científico sino en el contable, sin el cual seria irrealizable el primero. Por nuestra parte hacemos entrega de esta Secretaría con la satisfacción del deber cumplido, pese a las dificultades inherentes al ejercicio profesional, que no en todos los casos permite disponer del tiempo suficiente para laborar más aún en beneficio de la Sociedad. 